\title{
The singularity of indeterminates: Number specification without classifiers
}

\author{
Ken Hiraiwa*
}

\begin{abstract}
Japanese does not have number morphology or agreement. Thus, a bare noun like inu 'dog' can refer to a single dog or more than one dog, depending on contexts. This fact has raised much controversy about whether grammatical number exists in Japanese and has led some researchers to regard Japanese as a language lacking number specification in bare nouns (Chierchia 1998; Martin 1975; Nakanishi \& Tomioka 2004; Nomoto 2013) and abstract number/phi agreement (Fukui 1986, 1995, Kuroda 1988; Fukui and Sakai 2003, Saito 2007, 2017, among others). Recently, however, Watanabe (2017) has provided strong evidence against such views, based on partitive interpretations of bare nouns. In this paper, I uncover yet another novel piece of evidence for grammatical number specification in Japanese from indeterminates. Surprisingly, they are obligatorily specified for singular despite the lack of number morphology or classifier.
\end{abstract}

Keywords. number; indeterminates; singular/plural distinction; mass/count distinction; classifiers; indefinite pronouns

1. Introduction. Japanese does not have number morphology or agreement. Thus, a bare noun like inu 'dog' can refer to a single dog or more than one dog, depending on contexts. Even though there are three plural morphemes -tati, -ra, and -domo, these are only optional and limited to human (and some animate) nouns (see Nakanishi and Tomioka 2004). This fact has raised much controversy about whether grammatical number exists in Japanese and led some researchers to regard Japanese as lacking number specification in bare nouns (Chierchia 1998; Martin 1975; Nakanishi \& Tomioka 2004; Nomoto 2013) or abstract number/phi agreement (Fukui 1986, 1995, Kuroda 1988; Fukui and Sakai 2003, Saito 2007, 2017, among others). Recently, however, Watanabe (2017) has provided strong evidence against such views, based on partitive interpretations of bare nouns.

In this paper, I uncover yet another novel piece of evidence for grammatical number specification in Japanese from indeterminates. Surprisingly, they are obligatorily specified for singular despite the lack of number morphology or classifier.

2. Indeterminate system. Japanese has an indeterminate system, in which each indeterminate pronoun (e.g. dare, nani, doko, dotti) is combined with a quantificational particle ( $k a$ or $m o$ ) to form different indefinite expressions (Kuroda 1965, 2013, Takahashi 2002, Shimoyama 2008, Hiraiwa 2015, 2017b, among others). Table 1 shows four indeterminate phrases, wh-phrases, universal quantifiers, existential quantifiers, and negative polarity items. Universal quantifiers and NPIs are morphologically identical but distinguished by pitch accent, which is indicated by diacritic "'. Hiraiwa $(2015,2017 b)$ shows that indeterminate phrases come in two category types, a full DP and a QP: the former requires case-marking and the latter resists case-marking.

\footnotetext{
* I would like to thank Chris Collins, Tomohiro Fujii, Yosho Miyata, Kimiko Nakanishi, Uli Sauerland, Anna Szabolsci, and the audience at the 93rd Annual Meeting of the Linguistic Society of America for helpful comments and discussions. This research has been funded by the JSPS Grant-in-Aid for Scientific Research (C) (No. 16K02645), to which I am grateful. Author: Ken Hiraiwa, Meiji Gakuin University (hiraiwa@1tr.meijigakuin.ac.jp).
} 


\begin{tabular}{cccccc} 
& & DP & DP & DP & QP \\
\hline & $\begin{array}{c}\text { Indeterminate } \\
\text { Pronouns }\end{array}$ & $\begin{array}{c}\text { Wh } \\
\text { 'wh X' }\end{array}$ & $\begin{array}{c}\text { Universal } \\
\text { 'every X' }\end{array}$ & $\begin{array}{c}\text { Existential } \\
\text { 'some X' }\end{array}$ & $\begin{array}{c}\text { NPI } \\
\text { 'any X' }\end{array}$ \\
\hline who & dare & da're ... ka & da're-mo & da're-ka & dare-mo \\
what & nani & na'ni ... ka & -1 & na'ni-ka & nani-mo \\
where & doko & do'ko ... ka & do'ko-mo & dok'o-ka & doko-mo \\
which & dotti & do'tti ... ka & do'tti-mo & do'tti-ka & dotti-mo \\
\hline
\end{tabular}

Table 1: indeterminate system in Japanese (partial)

As the data in Table 1 shows, indeterminate phrases in Japanese, like ordinary nouns, do not show any morphology of singular and plural distinction. They are incompatible with optional plural morphemes (e.g. *dare-\{tati/ra/domo\} 'who-Pl', *dare-ka-\{tati/ra/domo\} 'someone-Pl'). In what follows, however, I will demonstrate that they are specified for singular based on four diagnostic tests. ${ }^{2}$ For example, dare-ka 'someone' only allows for singular interpretation. Their singularity, if true, is surprising in two respects. First, Japanese nominals have been considered to be number neutral. Second, there is no a priori reason why indefinite pronouns must be semantically singular. In fact, as the data provided by Anna Szabolsci p.c. shows, indeterminate phrases in Hungarian do show singular/plural morphology.

(1) Hungarian ${ }^{3}$
a. valaki
'someone (singular)' valakik 'someone (plural)'
b. valami
'something (singular)' valamik 'something (plural)'
c. mindenki
'everyone (singular)'
mindenkik 'everyone (plural)'
d. minden 'everything (singular)'
mindenek
'everything (plural)'
e. bárki 'anyone (singular)'
bárkik
'anyone (plural)'
f. akárki
akárkik
'anyone (plural)'

3. Floating numeral quantifier test. First, a floating numeral test shows that existential indeterminate phrases (e.g. dare-ka 'someone' and nani-ka 'something') and complex existential indeterminate phrases (e.g. dono-hito-ka (wh-person-Q) 'someone') are only compatible with a numeral one, as shown in example (2). The same is true of existential indeterminate phrases, as shown in (3). This indicates that existential indeterminate phrases in Japanese can never be interpreted as plural (i.e. 'some people' or 'some things') and rather are obligatorily specified for singular number, even though there is no overt morphology or classifiers on them.

\section{(2) Japanese}

Taro, Jiro, Saburo, Shiro, Goro no naka kara

Taro, Jiro, Saburo Shiro Goro Gen among from

\{dare-ka-o/dono-hito-ka-o $\}$ \{hito-ri/*huta-ri/*san-nin $\}$-dake erande.

\footnotetext{
${ }^{1}$ See Hiraiwa (2017) for a principled explanation for the gap and decomposition of indeterminate pronouns.

${ }^{2}$ Due to differences in the nature of each diagnostic tests, it is not always possible to test each type of indeterminate phrases below.

${ }^{3}$ I am grateful to Anna Szabolcsi for providing me with the data. It should be noted that although the indefinites in (1) show singular/plural distinction morphologically, their interpretations in contemporary Hungarian are complicated and not straightforward. I will not go into details in this short paper.
} 
who-Q-Acc/wh-person-Q-Acc 1-Cl/2-Cl/3-Cl-only

choose

'Please pick up only one/two/three among Taro, Jiro, Saburo, Shiro, and Goro.'

(existential)

(3) Japanese

Ringo, banana, itigo, budoo, orenzi no naka kara

apple banana strawberry grape orange Gen among from

nani-ka-o $\quad\{$ hito-tu/*?huta-tu/*?mit-tu $\}$-dake erande.

what-Q-Acc 1-Cl/2-Cl/3-Cl-only choose

'Please pick up only one/two/three among apples, bananas, strawberries, grapes and oranges.'

(existential)

4. Partitive test. Second, a partitive test shows us that wh-indeterminate phrases and existential indeterminate phrases are obligatorily specified for singular. As Watanabe (2017) observes, a partitive expression 'a part of $\mathrm{X}$ ' is semantically ambiguous when $\mathrm{X}$ is a countable noun: depending on $\mathrm{X}$ is singular or plural, as in (4). When $\mathrm{X}$ is singular, it only has a physical part reading. In contrast, when $\mathrm{X}$ is plural, it has a subset reading. If we use indeterminate phrases as in (5a)-(5c), however, the sentences are unambiguous and only mean 'a (body) part of someone/who'.

\section{(4) Japanese}

gakusee no itibu

student Gen part

'a body part of a/the student' (singular)

'a subset of (the) students' (plural)
a. dare-ka no itibu
who-Q Gen part
'a body part of someone'
'*a subset of some people'
b. dare no itibu
who Gen part
'a body part of who'
'*a subset of which people'
c. dare-mo no itibu
who-Q Gen part
'a body part of everyone'
'*a subset of all the people'
d. nani-ka no itibu
what-Q Gen part
'a (body) part of something'
"??a subset of some things'

\footnotetext{
${ }^{4}$ Nani- $k a$ 'something' in Japanese can refer to a discrete object or substance. Thus, example (5d) is fine under an interpretation 'some portion of salt'. This indicates that the existential indeterminate phrase nani-ka is not specified for singular when it refers to substance.
} 
If indeterminate phrases were numerically neutral, then they would allow for a subset reading. Thus, the data in (5) demonstrates that indeterminate phrases in Japanese are obligatorily specified for singular. ${ }^{5}$

5. Distributive/Collective test. Third, universal indeterminate phrases only allow for a distributive reading when used with a predicate such as 'heavy' (see Schwarzchild 2011).

Example (6), where the subject is a plural count noun phrase, is ambiguous between a collective reading where the total weight of the boxes is heavy and a distributive reading where the weights of the individual boxes are heavy.

(6) The boxes are heavy.

(Schwarzchild 2001, 662)

Similarly, example (7) with a bare noun hito 'person' is ambiguous between a distributive reading (i.e. the weight of each individual person was heavy) and a collective reading (i.e. the total weight of the people was heavy (although some of them may not be heavy)). This is not surprising because a bare noun in Japanese can be singular or plural.

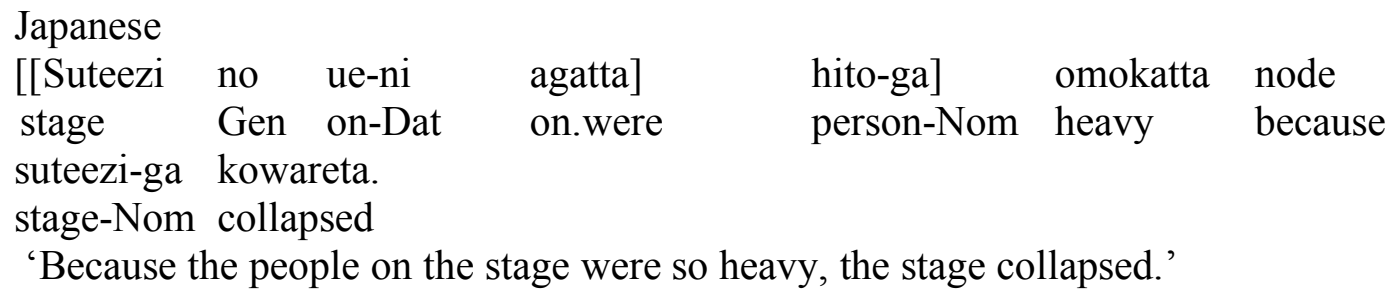

( $\checkmark$ distributive $/ \mathcal{}$ collective)

Now compare examples (7) and (8). Universal indeterminate phrases (e.g. dare-mo 'everyone') and complex universal indeterminate phrases (e.g. dono-hito-mo (wh-person-also) 'every person'), unlike bare nouns, do not yield a collective reading. In other words, for example (8) to be true, every one of the people that were on the stage must be heavy.

(8) Japanese

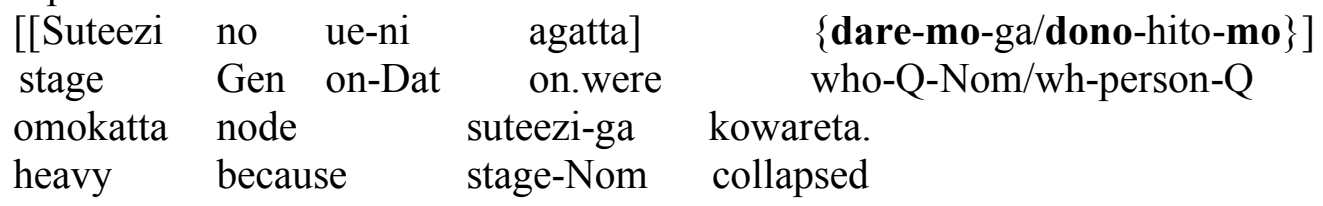

'Because the people on the stage were so heavy, the stage collapsed.'

( $\checkmark$ distributive/*collective)

\footnotetext{
${ }^{5}$ It is not the case that the category of pronouns in Japanese are generally specified for singular. Plural personal pronouns do allow for a subset reading.

(i) Japanese

\{wareware/kimitati/karera\} no itibu

$1 \mathrm{Pl} / 2 \mathrm{Pl} / 3 \mathrm{Pl}$ Gen part

'a subset of us/you/them'
} 
Assuming that a collective reading requires a plural noun or a mass noun, the fact that a collective reading disappears with universal indeterminate phrases in (8) shows that they are specified for singular number.

6. Collective Predicate Test. Finally, collective predicates also support our claim. Some predicates such as atumaru 'get together' require plural subjects. Thus, the bare noun in example (9) necessarily receives a plural interpretation. Similarly, the proper noun Ken cannot be interpreted as singular. Rather, it must be interpreted as a plural bare noun.

Japanese
a. Gakusee-ga atumatteiru. student-Nom got.together
'Students got together.' '*A/The student got together.'
b. Ken-ga atumatteiru.
Ken-Nom got.together
'*Ken got together.' 'People named Ken got together.'

If an indeterminate phrase in Japanese, like a bare noun, were ambiguous between singular and plural, it would be compatible with a collective predicate. Examples (10), however, show that it is illicit, which in turn presents evidence that indeterminate phrases in Japanese are specified for singular.

(10) Japanese
a. *Dare-ka-ga atumatteiru. who-Q-Nom got.together
'Someone got together.' 'Some people got together.'
b. *Dare-mo-ga atumatteiru. Who-Q-Nom got.together
'Everyone got together.'
c. *?Dono-hito-mo atumatteiru. wh-person-Q got.together
'Every person got together.' what-Q-Nom got.together 'Something (i.e. animals) got together.'
d. *Nani-ka-ga atumatteiru.

\footnotetext{
${ }^{6}$ Definite singular nouns in Japanese seem to allow a type reading. Thus, example (i) is compatible with the numeral go 'five', even though the definite noun phrase kono hon 'this book' is clearly singular both morphologically and contextually.
}

(i)

Japanese
Kono hon-o go-satu katta.
this.Sg book-Acc 5-Cl bought
'I bought five copies of this book.'

There may be speakers who find (10d) marginally acceptable, but in that case, the sentence may have the same type reading as (i). 
7. The locus of number: Arguments vs. adjuncts. While I have demonstrated so far that indeterminate phrases in Japanese are specified for singular, such an example as (11) may appear to refute our claim because the indeterminate phrase co-occurs with singular as well as non-singular numerals.

\section{(11) Japanese}

Taro, Jiro, Saburo, Shiro, Goro no naka kara

Taro, Jiro, Saburo Shiro Goro Gen among from

dare-ka $\{$ hito-ri/huta-ri/san-nin $\}$-dake erande.

who-Q 1-Cl/2-Cl/3-Cl-only choose

'Please pick up only one/two/three among Taro, Jiro, Saburo, Shiro, and Goro.'

In fact, it is this kind of data that has deluded us (and indeed one of the reviewers) into believing that indeterminate phrases are never specified for number, like ordinary nouns. A mere glance at the data, however, immediately reveals that such objection is plain wrong. Note that in example (11), dare-ka 'something' does not function as object: if it were, it should receive accusative case-marking. And in fact, if it is marked by accusative case, the example becomes ungrammatical as we have seen in example (2).

As I mentioned in Section 2, some indeterminate phrases in Japanese resist case-marking (see Aoyagi \& Ishii 1994, Hiraiwa 2015, 2017b). For example, negative polarity items cannot be case-marked, as shown in (12a). Similarly, an existential indeterminate phrase can also appear without case-marking, as shown in (12b).

(12) Japanese

a. (Gakusee-ga) dare-mo(*-ga) konakatta. student-Nom who-Q(-Nom) came.not

No students came.'

b. (Gakusee-ga) dare-ka kita. student-Nom who-Q came

'A student came.'

Indeterminate phrases also appear case-less in 'something/anything/everything spicy' constructions. (see Hiraiwa 2018 for a detailed analysis).

(13) Japanese

Nani-ka karai mono-o tabeta. what-Q spicy thing-Acc ate 'I ate something spicy.'

In all of these examples, case-less indeterminate phrases co-occur with case-marked true argument DPs. This means that they are not DPs but adjuncts/adverbials, possibly QPs (see Section 2; see also Hiraiwa 2015, 2017b, 2018). Thus, it is no wonder that the singular number specification is limited to argument indeterminate phrases, because only nouns (i.e. DPs) are supposed to have phi-features and adjuncts/adverbials lack them.

Where are the phi-features located? One might think that the quantificational particles $k a$ and $m o$ are the locus of singularity of indeterminates. However, this is not true. For one thing, as 
we have seen just above, adjunct/adverbial indeterminate phrases do not have number specification, even though they contain $k a$ or mo. For another, a plural ordinary noun can be combined with these particles, but it is still semantically plural.

(14) Japanese
a. san-satu no hon mo ...
3-Cl Gen book Q
'three books also ...'
b. Ken-tati mo ...
Ken-P1 Q
'Ken and others also ...'
$\begin{array}{lllll}\text { c. san-satu } & \text { ka } & \text { sokora } & \text { no } & \text { hon } \\ 3-\mathrm{Cl} & \mathrm{Q} & \text { so } & \text { Gen } & \text { book }\end{array}$
'three books or so'

Thus, the locus of phi-features is at least other than the quantificational particles and must be structurally higher than QP.

8. Wh-indeterminate phrases. The only systematic exception to our claim that indeterminate phrases are specified for singular is wh-indeterminate phrases. While the partitive test in (15) shows that dare 'who' is specified for singular, the collective predicate test in (16) indicates that it is not specified for singular.

(15) Japanese

Dare no itibu?

Who Gen part

'Whose body part is it?'

'*What people/Who are they a part of?'

(16) Japanese

Dare-ga atumatta no?

who-Nom got.together C

'Who got together?'

Example (16) would be ungrammatical if dare 'who' were always singular, because the collective predicate requires a plural subject.

The fact that wh-question does not require a singular answer may also support the observation that the wh-phrase is not specified for singular. In example (17), the wh-indeterminate phrase dare 'who' is compatible with the plural answer.

(17) Japanese

Q: dare-ga kita no?
who-Nom came C
'Who came?'
A: Ken to Naomi.
Ken and Naomi
'Ken and Naomi.' 
Uli Sauerland p.c. informs me, however, that in Hungarian and Spanish, even though their whphrases 'who' show singular/plural distinction, a singular wh-phrase accepts a plural answer. If so, the question-answer test may not be a reliable test for singularity. ${ }^{7}$

Finally, there are languages that show morphological singular/plural distinction in whphrases. ${ }^{8}$

(18) Okinawan

$\begin{array}{ll}\text { taa } & \text { tat-taa } \\ \text { who.Sg } & \text { who-Pl } \\ \text { 'who (singular)' } & \text { 'who (plural)' }\end{array}$

(19) Miyakoan (Shimoji 2018, 155)

taa taa-du

who.Sg who-Pl

'who (singular)' 'who (plural)'

(20) Buli

wa-na ba-na

NC.Sg-who NC.Pl-who

'who (singular)' 'which people (plural)'

(21) Mongolian (Haspelmath 1997)

juu juu-juu

what.Sg what-what

'what (singular) 'what (plural)'

\footnotetext{
${ }^{7}$ Yosho Miyata (p.c.) points out that unlike other wh-indeterminates phrases, doitu 'which person' is specified for singularity.

(i) Japanese

*Doitu-ga atumatteriu no?

which.person-Nom got.together C

'Which people got together?'

(ii) Japanese

*Doitu no itibu

which.person Gen part

'a body part of who'

'*a subset of which people'

doitu is interesting because it shows singular/plural morphological distinction (doitu 'which person' vs. doitura 'which people'). This may be related to a possibility that doitu is actually derived from a complex wh-phrase doyatu consisting of an indeterminate $d o$ (which) and a light noun/pronoun yatu 'guy'. If that is the case, then it explains why it apparently has singular/plural morphological distinction. Note that a third person pronoun yatu is specified for singular, while yatura is plural.

${ }^{8}$ I am grateful to Chie Inamine (Okinawan) and Abdul-Razak Sulemana (Buli) for the data. According to AbdulRazak Sulemana p.c., it is also to form make a wh-phrase plural by conjunction in Buli (e.g. wana ali wana 'who and who').
} 
(22) Tagalog (Haspelmath 1997)

sino sinu-sino

who.Sg who-who

'who (singular)' 'who (plural)'

There seems to be a cross-linguistic tendency that languages, if they do at all, show number distinction in wh-phrases rather than in other indefinite pronouns. In this respect, Japanese is no exception, even though it does not make a morphological distinction in wh-indeterminate phrases.

9. Conclusion and consequences. It is a mistake to conclude that Japanese lacks a category of grammatical number, merely based on the absence of overt number morphology and the presence of classifiers. Such a conclusion is proven to a hasty one if we take a look at personal pronouns, which obligatorily require a plural morpheme. In this paper, however, I have added yet another piece of evidence for number specification in Japanese. But indeterminate phrases are different from those personal pronouns in one important respect: they do not show morphological singular/number distinction, but are nevertheless obligatorily specified for singular. Furthermore, this number specification is independent of the use of classifiers, suggesting that classifiers are not the locus of number distinction, contra the common view.

This paper is still preliminary and leaves a theoretical explanation for the singularity of indeterminate phrases for future research. The present results still have many ramifications, however. First, it follows that Japanese does have a category of grammatical number, supporting Watanabe (2010, 2017). Its existence is naturally expected, if Hiraiwa's (2017a) claim that grammatical number (singular-dual-plural) is founded on the Approximate Number System (ANS) and hence universally available to the human language faculty (see Feigenson, Dehaene, and Spelke 2004 for the ANS and Hiraiwa 2017a for a hypothesis about how capacities for natural numbers could arise from integrating the two cognitive systems of number and Merge in Chomsky 2008).

Second, it seems that in a number of languages of the world, indefinite pronouns tend to be singular in the absence of morphological number marking. It is, thus, interesting to examine whether the singularity of indefinite pronouns is universal or not in the future.

Third, it necessitates re-evaluation of Gentner and Imai's (1987) experimental work. They discovered that speakers of languages that show grammatical number morphology (English) and those that do not (e.g. Japanese) generalize simple object instances and substance instances differently. Given the demonstration that Japanese in fact does have number distinction even though it is phonologically invisible, the different cognitive behaviors that their experimental studies brought to light may be superficial and could be linked to processing rather than a deep difference in linguistic structures between the two languages.

\section{References}

Aoyagi, Hiroshi, and Toru Ishii. 1994. On agreement-inducing vs. non-agreement-inducing NPIs. In Merce Gonzalez (ed.), The proceedings of NELS 24. 1-15. Amherst, MA: GLSA. Chierchia, Gennaro. 1998. Reference to kinds across languages. Natural Language Semantics 6(4). 339-405. https://doi.org/10.1023/A:10083242.

Chomsky, Noam. 2008. On phases. In Robert Freidin, Carlos P. Otero \& Maria Luisa Zubizarreta (eds.), Foundational issues in linguistic theory. Essays in honor of Jean-Roger Vergnaud. 133-166. Cambridge, MA: MIT Press.

Feigenson, Lisa, Stanislas Dehaene \& Elizabeth S. Spelke. 2004. Core systems of number. 
Trends in Cognitive Sciences 8(7): 307-314. https://doi.org/10.1016/j.tics.2004.05.002

Fukui, Naoki. 1986. A theory of category projection and its theoretical applications. Cambridge, MA: MIT dissertation.

Fukui, Naoki and Hiromu Sakai. 2003. The visibility guideline for functional categories: verb raising in Japanese and related issues. Lingua 113(4-6). Special Issue, Formal Japanese syntax and universal grammar: The past 20 years. 321-375. https://doi.org/10.1016/ S0024-3841(02)00080-3.

Kuroda, S.-Y. 1965. Generative grammatical studies in the Japanese language. Cambridge, MA: MIT dissertation.

Kuroda, S.-Y. 1988. Whether we agree or not: A comparative syntax of English and Japanese. Linguisticae Investigations 12(1). 1-47. https://doi.org/10.1075/li.12.1.02kur.

Kuroda, S.-Y. 2013. Prosody and the syntax of indeterminates. Lingua 124. 64-95. https://doi.org/10.1016/j.lingua.2012.10.013

Haspelmath, Martin. 1997. Indefinite pronouns. New York, NY: Oxford University Press.

Hiraiwa, Ken. 2015. The QP syntax: noun class, case, and augment. In Thuy Bui \& Deniz Özidiz (eds.), The proceedings of NELS 45, vol.2. 1-11. Amherst, MA: GLSA.

Hiraiwa, Ken. 2017a. The faculty of language integrates the two core systems of number. Frontiers in Psychology 8:351. https://doi.org/10.3389/fpsyg.2017.00351.

Hiraiwa, Ken. 2017b. Labeling roots: indeterminates and particles. In Andrew Lamont \& Katerina Tetzloff (eds.), The proceedings of NELS 47, vol. 2. 79-88. Amherst, MA: GLSA.

Hiraiwa, Ken. 2018. Something visible in Japanese. Glossa 3(1): 132. 1-23. https://doi.org/10.5334/gjgl.361.

Imai, Mutsumi \& Dedre Gentner. 1997. A crosslinguistic study of early word meaning. Cognition 62. 169-200. https://doi.org/10.1016/S0010-0277(96)00784-6.

Martin, Samuel E.. 1975. A reference grammar of Japanese. New Haven and London: Yale University Press.

Nakanishi, Kimiko and Satoshi Tomioka. 2004. Japanese plurals are exceptional. Journal of East Asian Linguistics 13(2). 113-140. https://doi.org/10.1023/B:JEAL.0000019058.46668.c1.

Nomoto, Hiroki. 2013. Number in classifier languages. Minneapolis, MN: University of Minnesota dissertation.

Saito, Mamoru. 2007. Notes on East Asian argument ellipsis. Language Research 43. 203-227.

Saito, Mamoru. 2017. Japanese wh-phrases as operators with unspecified quantificational force. Language and Linguistics 18(1): 1-25.

Schwarzchild, Roger. 2011. Stubborn distributivity, multiparticipant nouns and the count/mass distinction. In Suzi Lima, Kevin Mullin \& Brian Smith (eds.), The proceedings of NELS 39 , vol. 2. 661-678. Amherst, MA: GLSA.

Shimoji, Michinori. 2018. Minami Ryukyu Miyakogo Irabu Hogen (Irabu, A Southern Ryukyu Miyakoan). Tokyo: Kurosio.

Shimoyama, Junko. 2008. Indeterminate pronouns. In Shigeru Miyagawa \& Mamoru Saito (eds.), The Oxford handbook of Japanese linguistics. 372-393. New York, NY: Oxford University Press. https://doi.org/10.1093/oxfordhb/9780195307344.013.0014.

Takahashi, Daiko. 2002. Determiner raising and scope shift. Linguistic Inquiry 33(4): 575-615. https://doi.org/10.1162/002438902762731772.

Watanabe, Akira. 2010. Vague quantity, numerals, and natural numbers. Syntax 13(1). 37-77. https://doi.org/10.1111/j.1467-9612.2009.00131.x.

Watanabe, Akira. 2017. The mass/count distinction in Japanese from the perspective of partitivity. Glossa 2(1): 98. 1-26. https://doi.org/10.5334/gjg1.116. 